OPEN ACCESS

Approved by:

Frontiers Editorial Office,

Frontiers Media SA, Switzerland

*Correspondence:

Mohamed Gharibi

mggv@@mail.umkc.edu

Specialty section:

This article was submitted to

Data Mining and Management,

a section of the journal

Frontiers in Big Data

Received: 01 May 2020

Accepted: 12 May 2020

Published: 10 June 2020

Citation:

Gharibi M, Zachariah A and Rao $P$ (2020) Corrigendum: FoodKG: A Tool

to Enrich Knowledge Graphs Using

Machine Learning Techniques.

Front. Big Data 3:21.

doi: 10.3389/fdata.2020.00021

\section{Corrigendum: FoodKG: A Tool to Enrich Knowledge Graphs Using Machine Learning Techniques}

\author{
Mohamed Gharibi ${ }^{1 *}$, Arun Zachariah ${ }^{2}$ and Praveen Rao ${ }^{2,3}$ \\ 'Department of Computer Science and Electrical Engineering, University of Missouri-Kansas City, Kansas City, MO, \\ United States, ${ }^{2}$ Department of Electrical Engineering and Computer Science, University of Missouri-Columbia, Columbia, \\ MO, United States, ${ }^{3}$ Department of Health Management and Informatics, University of Missouri-Columbia, Columbia, MO, \\ United States
}

Keywords: machine learning, graph embeddings, knowledge graphs, AGROVOC, semantic similarity

\section{A Corrigendum on}

FoodKG: A Tool to Enrich Knowledge Graphs Using Machine Learning Techniques

Gharibi, M., Zachariah, A., and Rao, P. (2020). Front. Big Data 3:12. doi: 10.3389/fdata.2020.00012

In the published article, there was an error in the affiliation of the first author. Instead of the "University of Missouri-Columbia," the university name should be "University of MissouriKansas City."

The authors apologize for this error and state that this does not change the scientific conclusions of the article in any way. The original article has been updated.

\footnotetext{
Copyright (c) 2020 Gharibi, Zachariah and Rao. This is an open-access article distributed under the terms of the Creative Commons Attribution License (CC BY). The use, distribution or reproduction in other forums is permitted, provided the original author(s) and the copyright owner(s) are credited and that the original publication in this journal is cited, in accordance with
} accepted academic practice. No use, distribution or reproduction is permitted which does not comply with these terms. 